\title{
Facial disfigurement
}

Krysia Saul, who was severely disfigured by a dog attack at age 5, describes the process of coming to terms with her appearance and others' attitudes

\author{
Krysia Saul researcher ${ }^{1}$, Jill E Thistlethwaite professor ${ }^{2}$ \\ ${ }^{1}$ Warwick Medical School, University of Warwick, Coventry CV4 7AL, UK; ${ }^{2}$ University of Queensland, School of Medicine, Herston, Australia
}

This is one of a series of occasional articles by patients about their experiences that offer lessons to doctors. The BMJ welcomes contributions to the series. Please contact Peter Lapsley (plapsley@bmj.com) for guidance.

Essex, 1955, approaching my sixth birthday; dad had agreed to do some carpentry work in our landlady's house, so I accompanied him. While he worked I explored the grounds looking for chickens. No chickens, but an Alsatian dog, chained since a puppy to his kennel. On that day the dog broke free and attacked me. It tore the skin from my back, pierced a lung, and savaged my right cheek, leaving a ragged hole from my ear to the corner of my mouth through which my tongue and teeth were visible.

I was rushed to Mount Vernon Hospital, then one of the few specialist centres for reconstructive surgery. I was not expected to survive, and treatment focused on keeping me alive. Surgeons had no experience of this kind of trauma or of the surgical techniques required to reconstruct my face. Initially they patched my face with a skin graft from my leg so that my cheek looked like one of Dad's darned socks.

Later, when my face had grown to its adult size, a pedicle flap was taken from my stomach and placed over the graft-a process that took several operations, each requiring a long stay in hospital. Journeys to the hospital by public transport seemed lengthy and arduous; my parents rarely visited because the travelling costs were so high. I read voraciously, acquiring the vocabulary of a much older child; my resilience is probably rooted in this phase of my life.

Most of the operations occurred throughout my time at junior school, when I must have looked like a patchwork doll. I became an object of curiosity and felt uncomfortable with others' attitudes towards my appearance. At a bus stop, two women remarked that I shouldn't be allowed out in public; another whispered that I should have been put down at birth. Outside a shop, a woman wearing dark glasses stared persistently, unaware that I could see her looking at me. Though hot with embarrassment, I glared back. Nowadays I smile if someone stares; they usually smile back or look away. To those who continue to stare I laughingly offer a photograph to remember me by-which leaves them feeling uncomfortable, not me. Naughty, though!

To compensate for lost schooling, I spent the last years of my education at a boarding school, where I felt comfortable because no one paid any attention to my scar. But starting work marked the beginning of a deep self-consciousness. Travelling to London meant my using public transport, a journey I hated. On trains and buses I rushed to a window seat, so that my "good" side was visible to anyone sitting next to me. Some people stared behind their newspaper; others gazed with hostility as though I had done something to deserve my face. I read a book, did a crossword, pretended to be asleep, and hid beneath swathes of hair deliberately grown long - anything to avoid the public gaze. People's experience of visible difference and of dealing with it varies widely. Initially, I sought to achieve the flawless face portrayed in contemporary romantic novels through surgery. The final operation, instigated by me, was not a success, largely because of my unrealistic expectations. I reluctantly concluded that nothing would fully restore my face, so I had better learn to live with it.

Psychosocial support was never offered as an option. My general practitioner knew nothing about skin camouflage products and had little time for my concerns about self image. He even commented that I should be grateful to be alive at all. Yet camouflage became an important coping strategy, helping me literally to face the world with confidence, to express my identity, underpinning more sustaining coping behaviours and resilience. In my experience general practitioners know little about camouflage but will refer patients with disfigurement for surgical intervention. Some regard self image as a more difficult problem to resolve than disfigurement, as though they were separate issues.

In mid-1960s in Britain cosmetics generally, and camouflage products specifically, were neither as fashionable nor as 
accessible as in America. I researched the topic among the few beauty magazines available and wrote letters to "experts" and editors. I travelled to Scotland to visit Doreen Trust, who was born with a facial birthmark, and was the only person promoting camouflage makeup at that time. Camouflage products were not widely promoted, were expensive, and were available only by post from London. They came with little guidance, and early applications were frustrating, unpredictable, and time consuming. Dreadful colours, thick messy creams-facial Polyfilla. I cried for hours striving for the desired look. Today, several excellent brands are available on prescription and over the counter, and the British Association of Skin Camouflage provides training and support. Using camouflage routinely is a mixed blessing. Although it undoubtedly eased my transition from adolescent to adult in a society quickly becoming obsessed with facial perfection, successful application requires time, practice, and a good skin care regime. Users may become psychologically dependent on them but NHS-prescribed camouflage products are dermatologically tested and afford protection from the sun and harmful pollutants.

As a young adult I was anxious that my make-up would wear off, and I avoided social activities involving water, even though camouflage is waterproof when correctly applied. The prospect of sleeping with a guy raised concerns about the "big reveal." At what point in a relationship did one confess to looking worse without make-up, and how was I to "face up" the following morning? I slept with my make-up on and rose early to cleanse and reapply my face-which meant keeping my "kit" close by or ensuring that "sleeping" took place in my house. Intimacy and relationships pose substantial challenges for people with visible difference; especially if (as in the case of a former boyfriend) one's partner is obsessed with perfection. Nothing about me pleased him: my legs were too fat, my bust too small, and of course that scar was such an embarrassment. Worse, he wanted a naturally perfect face, free of blemish and artifice!

Some people are extraordinarily blunt and don't mince their words. Curiosity about my scar is understandable, but I bristle when asked, "What's wrong with your face?" That word "wrong" incenses me. There is nothing "wrong" with my face, although it is different. I tend to respond by playing dumb: "I give up, what is wrong with my face?" "What happened to your face?" comes a close second, though I also tell a nice story about the time I was tracking crocodiles on the Limpopo . . .

Healthcare professionals can also be insensitive. Comments like, "What an interesting scar," and, "What have you been up to then?" seem remarkably imperceptive to me. A psychologist suggested that, "People would soon get used to your scar without camouflage," unaware that it's not other people's feelings I'm concerned about. Healthcare professionals sometimes trivialise concerns that are related to appearance and approaching a general practitioner may require some mental preparation. Although disfigured, I am not ill, and I do not regard myself as a patient, but when visiting my general practitioner about skin problems even I feel compelled to legitimise the consultation through illness-as if mental wellbeing were less important.

Few general practices display leaflets on appearance-associated ailments, voluntary groups, or psychosocial support, although some refer patients for counselling. However I doubt they refer patients to organisations like Changing Faces, a charity specifically established to support people with visible difference regardless of cause or condition. Recently treated for breast cancer, I was surprised how little attention was paid to the potential distress patients might experience from an altered appearance resulting from aggressive treatments. Nurses, attempting to make light of the side effects of treatment, can appear to be dismissive of anxieties about self-image that will vary with the individual. Patients investing heavily in their self-image might benefit from psychosocial support and camouflage.

Camouflage also helped me focus on more absorbing aspects of life such as marriage and academia. I came late to both. My husband, Norman, imbued me with emotional well-being and self-worth and academia with intellectual self belief. I would rush through my morning regime in order to finish that essay, write that paper, study for exams. Naturally, I would prefer to have no scar. But camouflage serves as a useful prop, part of my armoury against society's unseemly battle with youth and perfection without resorting to surgery, which can never restore me to "normal." It helps me portray externally the "me" that lives inside.

Competing interests: All authors have completed the ICMJE uniform disclosure form at www.icmje.org/coi_disclosure.pdf (available on request from the corresponding author) and declare: no support from any organisation for the submitted work; no financial relationships with any organisations that might have an interest in the submitted work in the previous three years, no other relationships or activities that could appear to have influenced the submitted work.

Provenance and peer review: Not commissioned, not externally peer-reviewed.

Accepted: 21 July 2011

Cite this as: BMJ 2011;343:d5203

๑ BMJ Publishing Group Ltd 2011 


\section{A clinician's perspective}

I am not Krysia's doctor: I was her colleague and am a general practitioner and an educator. Krysia asked me to write this companion piece not only to add a doctor's perspective, but also to reflect on how we might improve the skills of health professionals in interacting with people with disfigurement. But, having written that sentence, I am reminded of Krysia's preference for the term "living with visible difference" as being a more inclusive and less value-laden description than disfigurement. When I first began working with Krysia at a UK medical school, of course I noticed her facial appearance but was not going to mention it, in the same way that I would not pass comment about someone with a missing limb or obvious neurological deficit. In social and (non-clinical) work circumstances we learn to notice but not question, certainly at least not until we have built a trusting and mutually respectful relationship. In our clinical roles, however, when we first meet a new patient we have to decide whether to ask and what to explore.

As a general practitioner the first consultation may be about symptoms or problems that seem unrelated to the disfigurement. Do we wait until the patient mentions it, perhaps when asked about their medical history? Or do we probe, potentially ineffectively, by asking: is there anything else you want to discuss? But this reflects on us, as health professionals, seeing the disfigurement as a problem, which it perhaps is not for the patient. However, in the early stages of a post-traumatic event like Krysia's, we need to be aware that there may be help we can offer. Patients may ask for help; if they do not, then we need to have the right words ready. We risk labelling someone like Krysia as being defined by her appearance. If we do decide to probe, we need to have some solutions available such as referral for camouflage for example, or the suggestion of a local self help group. And if we don't know of any possible solutions, we need to promise to find out, and follow-up on this promise. We must also remember that disfigurement is not always apparent-for example, a mastectomy, or severe scarring

I have learnt a lot from Krysia about Changing Faces and resilience. As doctors we are never totally off duty and our interactions with people in situations outside the surgery add to our experience of human life and adversity. The patient centred approach (including exploring ideas, concerns, and expectations) is obviously still applicable when interacting with patients with similar needs to Krysia's-she writes eloquently of her unrealistic expectations at one point in her journey. We cannot help rewrite expectations unless we know what they are.

Recruiting simulated patients with visible difference for generic consultations (that is, not specifically involving the "disfigurement") will help students and junior doctors practise how to approach such patients and ask questions. Simulated consultations may also address the disfigurement directly to allow learners to explore expectations and discuss strategies.

Jill E Thistlethwaite j.thistlethwaite@uq.edu.au

\section{Further reading}

The British Association of Skin Camouflage (http://www.skin-camouflage.net)—provides a comprehensive service for people who are interested in para-medical skin camouflage

The British Red Cross (www.redcross.org.uk/What-we-do/Health-and-social-care/Social-support-in-the-UK/Skin-camouflage)—-the charity has a team of trained volunteers who can teach people how to self-apply specialist cover creams

Changing Faces (www.changingfaces.org.uk) - a UK based charity giving support and information to people with disfigurements to the face, hands, or body, and their families 